\title{
Enucleation of pancreatic proinsulinoma: case report
}

\begin{abstract}
Functional islet beta-cell tumours represent $1 \%-2 \%$ of all pancreatic neoplasms. Diagnosing this type of tumour is often challenging because they present unspecific clinical features overlapping more common syndromes. Diagnosis involves expensive testing, so, establishing Whipple's triad and excluding causes of exogenous hyperinsulinemia is crucial before initiating investigation. During the investigation, identification of hypoglycaemia associated with inappropriately high levels of insulin and C-peptide should prompt the exclusion of rare causes of hypoglycaemia, including pancreatic islet-cells disease.
\end{abstract}

Surgical resection of pancreatic islet-cells adenoma is the primary treatment modality so, accurate localization of the tumour is important, as it enables more conservative intervention. In this paper, we describe a rare case of hypoglycaemia associated with endogenous hyperinsulinism and review important aspects of the diagnosis and treatment.

Keywords: proinsulinoma, hypoglycemia, islet beta-cells tumour, hyperinsulinism
Volume 3 Issue 5 - 2016

\author{
Ana Pires Goncalves,' Conceicao Viegas, ${ }^{2}$ \\ Madalena Lourenco, ${ }^{3}$ Hercilia Martins, ${ }^{4}$ Jorge \\ Pereira, ${ }^{5}$ Bruno Peixe, ${ }^{6}$ Ana Marta Nobre, ${ }^{7}$ \\ Sílvia Silva, ${ }^{8}$ Jorge Paulino Pereira, ${ }^{9}$ Mario \\ Lazaro $^{10}$ \\ 'Endocrinology's Division, CHAlgarve, Portugal \\ ${ }^{2}$ Internal Medicine Service, CHAlgarve, Portugal \\ ${ }^{3}$ Day Hospital Nurse, CHAlgarve, Portugal \\ ${ }^{4}$ Clinical Pathology Service, CHAlgarve, Portugal \\ ${ }^{5}$ Radiology Service, CHAlgarve, Portugal \\ ${ }^{6}$ Gastroenterology Service, CHAlgarve, Portugal \\ ${ }^{7}$ Hospital Curry Cabral, Portugal \\ ${ }^{8}$ Hospital Curry Cabral, Portugal \\ ${ }^{9}$ Hospital Curry Cabral, Portugal \\ ${ }^{10}$ Director of Internal Medicine Service, CHAlgarve, Portuga
}

Correspondence: Ana Pires Gonçalves, Endocrinologist at Centro Hospitalar do Algarve, Rua Leão Penedo, 8000-386, Faro, Portugal,Tel0 +35। 289 89/ 100,

Email aagoncalves@chalgarve.min-saude.pt

Received: September 05, 2016 | Published: November 28,

2016

\section{Introduction}

Functional islet beta-cells tumours represent $1 \%-2 \%$ of all pancreatic neoplasms. Diagnosing this type of tumour is often challenging because they present unspecific clinical features overlapping more common syndromes. Initially, autonomic symptoms are predominant during the hypoglycaemic episodes and later are followed by neuroglycopenic symptoms. Frequency and severity increases over time and syndrome of hypoglycaemia unawareness can be acquired as diminished counter regulatory hormone responses and adrenergic sensitivity establishes. Because of non-specific and insidious nature, the time between onset of symptoms and diagnosis is about 3 to 5 years.

In adults, hypoglycaemia is usually associated with an easily identifiable factor, such as known disease; medication or deficient counter regulatory insulin action hormones. However, in apparently healthy adults, other less common causes should be investigated. Investigation involves expensive testing, so, establishing Whipple's triad (plasma glucose less than $54 \mathrm{mg} / \mathrm{dL}$, with symptoms that reverse after administration of glucose) and excluding causes of exogenous hyperinsulinemia is crucial.

During an episode of spontaneous hypoglycaemia or fasting test (12 or 72 hours) the following findings suggest endogenous hyperinsulinemic hypoglycaemia: blood glucose $<55 \mathrm{mg} / \mathrm{dL}$ during a symptomatic period, associated with insulin $\geq 3 \mathrm{IU} / \mathrm{mL}$ or $18 \mathrm{pmol} / \mathrm{L}$ (ICMA)
(>6 IU/ml or $43 \mathrm{pmol} / 1$, (IRMA), C-peptide $\geq 200 \mathrm{pmol} / \mathrm{L}$ or $0.60 \mathrm{ng} /$ $\mathrm{ml}$, proinsulin $\geq 5 \mathrm{pmol} / \mathrm{L}$. Additionally, anti-insulin antibodies and antibody anti-receptor insulin should be dosed. ${ }^{1}$

In this paper, we describe a rare case of hypoglycaemia associated with endogenous hyperinsulinism, whose cause is uncommon in clinical practice, and review important aspects of the diagnosis and treatment.

\section{Case presentation}

A 47-year-old woman was sent to the endocrinology department for evaluation of suspected spontaneous hypoglycaemia. She wasn't taking any medications and reported no other medical problems. Her profession wasn't related to health care. For 2 years she had adrenergic/neuroglycopenic symptoms that relieved rapidly after ingestion of simple carbohydrate-containing food. She had gained $20 \mathrm{~kg} / 2$ years. Symptoms aggravated with time, with weekly frequency and incapacitation for work in last 6 months.

Fractionated-diet, excluding simple carbohydrates, failed to improve symptoms. The patient was taught how to use glucose meter to measure capillary blood glucose (BMT) and instructed to do a diary, that include meals content and BMT during symptoms. The diary revealed hypoglycaemias with values under $50 \mathrm{mg} / \mathrm{dL}$ associated with neuroglycopenia and without a predictable pattern. A mixed meal test was programed at the Day Care Hospital, that wasn't carried out be- 
cause the patient presented at 9 p.m. with neuroglycopenia, after 13 hours of fast.

Laboratorial investigation confirmed endogenous "hyperinsulinism" (Figure 1): venous glucose- $37 \mathrm{mg} / \mathrm{dL}$, unsuppressed peptide C $(2.3 \mathrm{ng} / \mathrm{mL})$, Serum-hydroxybutyrate levels at lower end of normal range $(0.07 \mathrm{mmol} / \mathrm{L})$, and after administration of $1 \mathrm{mg}$ of glucagon, glucose levels increased $35 \mathrm{mg} / \mathrm{dl}$. Autoimmunity was negative as were serum sulfonylurea levels. Insulinemia dropped to levels within normal range $(3.6 \mathrm{uUI} / \mathrm{mL})$, proinsulinemia was nine times the normal range $(47.3 \mathrm{pmol} / \mathrm{L})$. So we concluded that endogenous hyperinsulinism was secondary to autonomous proinsulin production ("pro-insulinoma").

The following exams were performed on the patient:

a) Ultrasound and a CT scan with contrast, which showed a single oval nodule with $17 \times 13 \mathrm{~mm}$ in relation to the duodenal part of the head of the pancreas with rapid clearance of the contrast, unidentifiable in portal phase or late acquisitions (Figure 2A-D).

b) Endoscopic Ultrasound, which confirmed a single nodule with very suggestive features of proinsulinoma (Figure 3). It was decided not to perform aspiration cytology.

The patient started treatment with diazoxide while waiting for surgery. She developed malleolar edema during treatment.

In September of 2014, she underwent a tumour enucleation, without complications (Figure 4). In the postoperative period the patient resolved symptoms and hypoglycaemia did not recur. The histopathological study confirmed a low-grade neuroendocrine tumour with high reactivity to a-chromogranin and synaptophysin (Figure 5A-D). Seven months post-surgery she didn't present hyperglycaemia or diabetes mellitus.

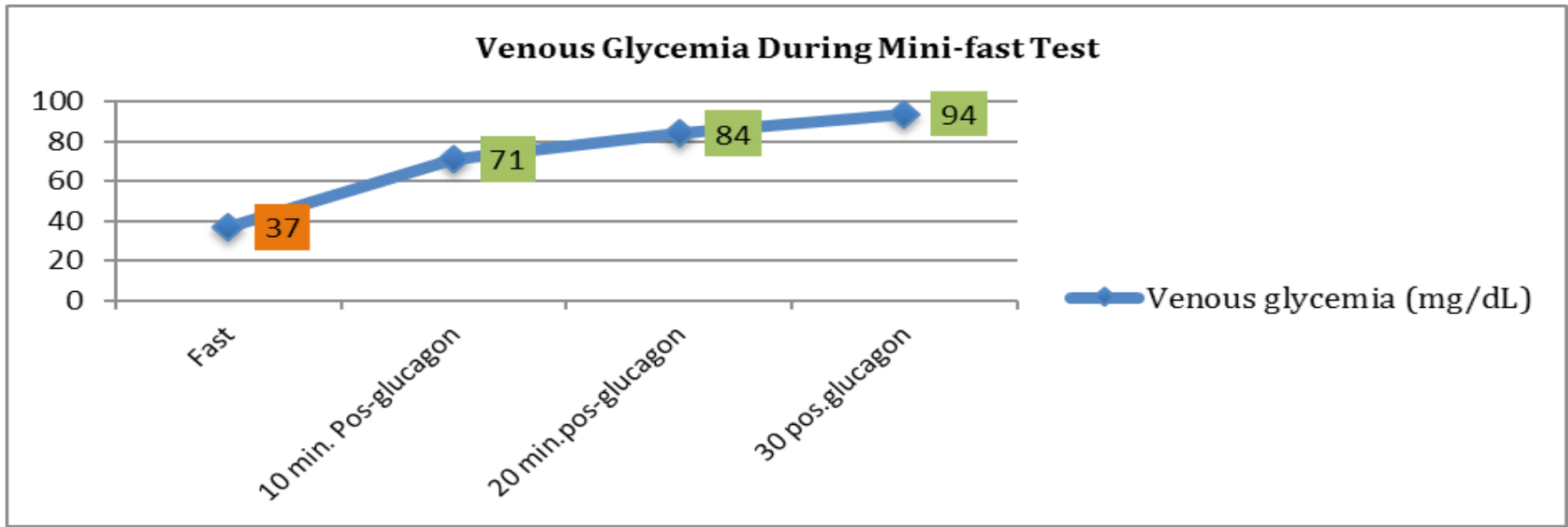

\section{Neuroglicopenia $(37 \mathrm{mg} / \mathrm{dL})$}

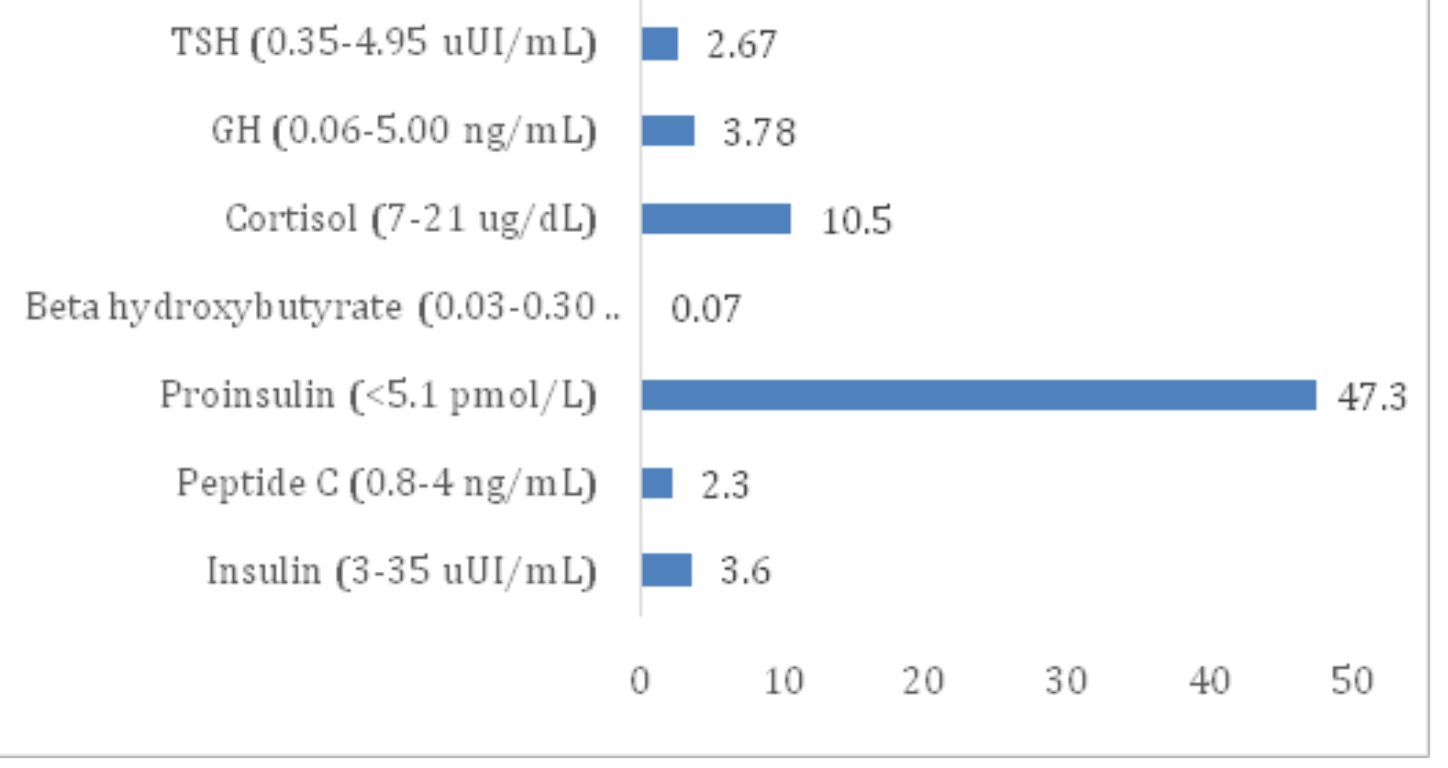

Figure I Endogenous hyperinsulinism secondary to autonomous proinsulin secretion. 


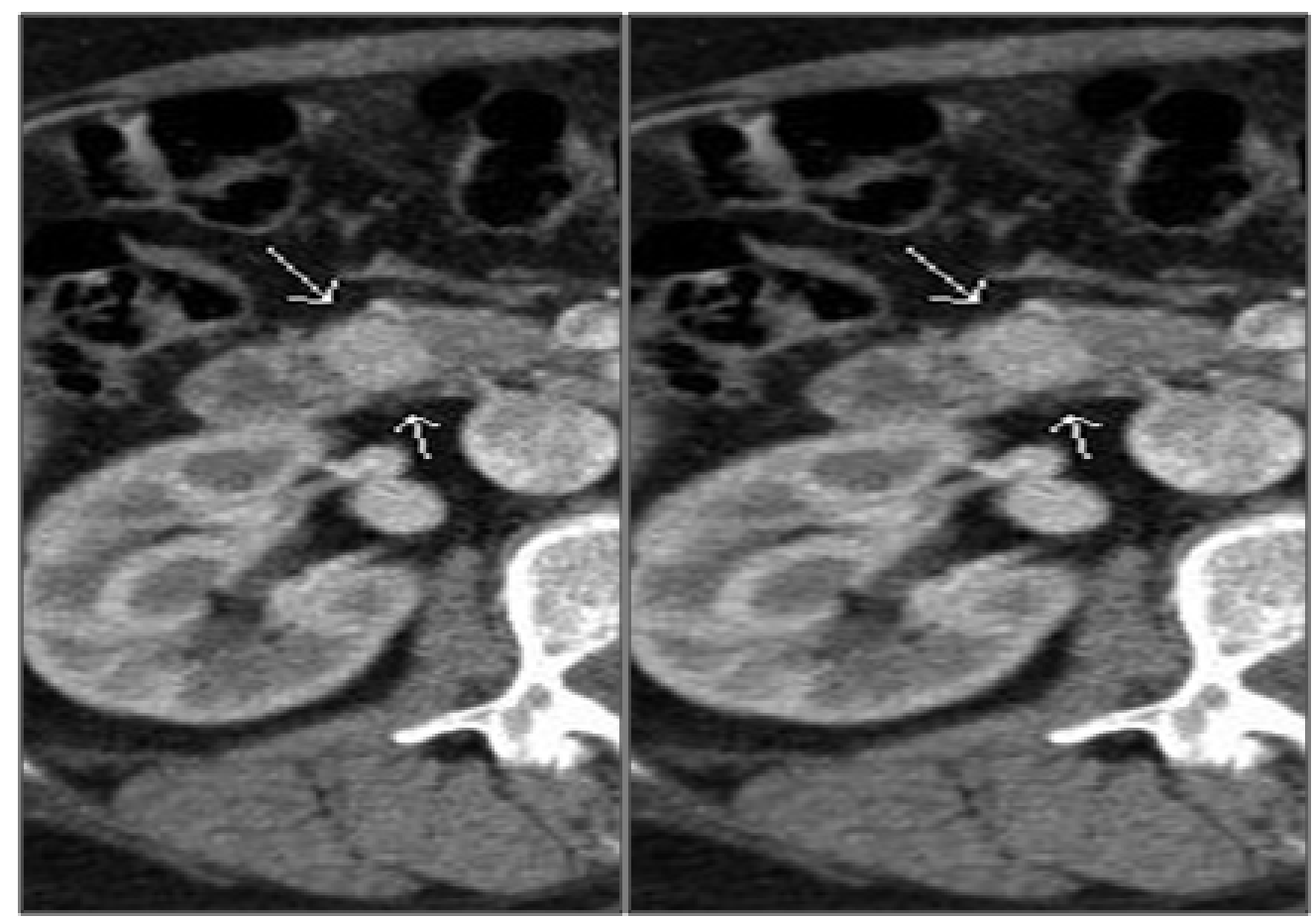

Nodule with greater enhancement than normal pancreas parenchyma during arterial and capillary phases (A/B), and rapid washout (C/D). A/B.Arterial phase. $C / D$. Early and late portal phase.
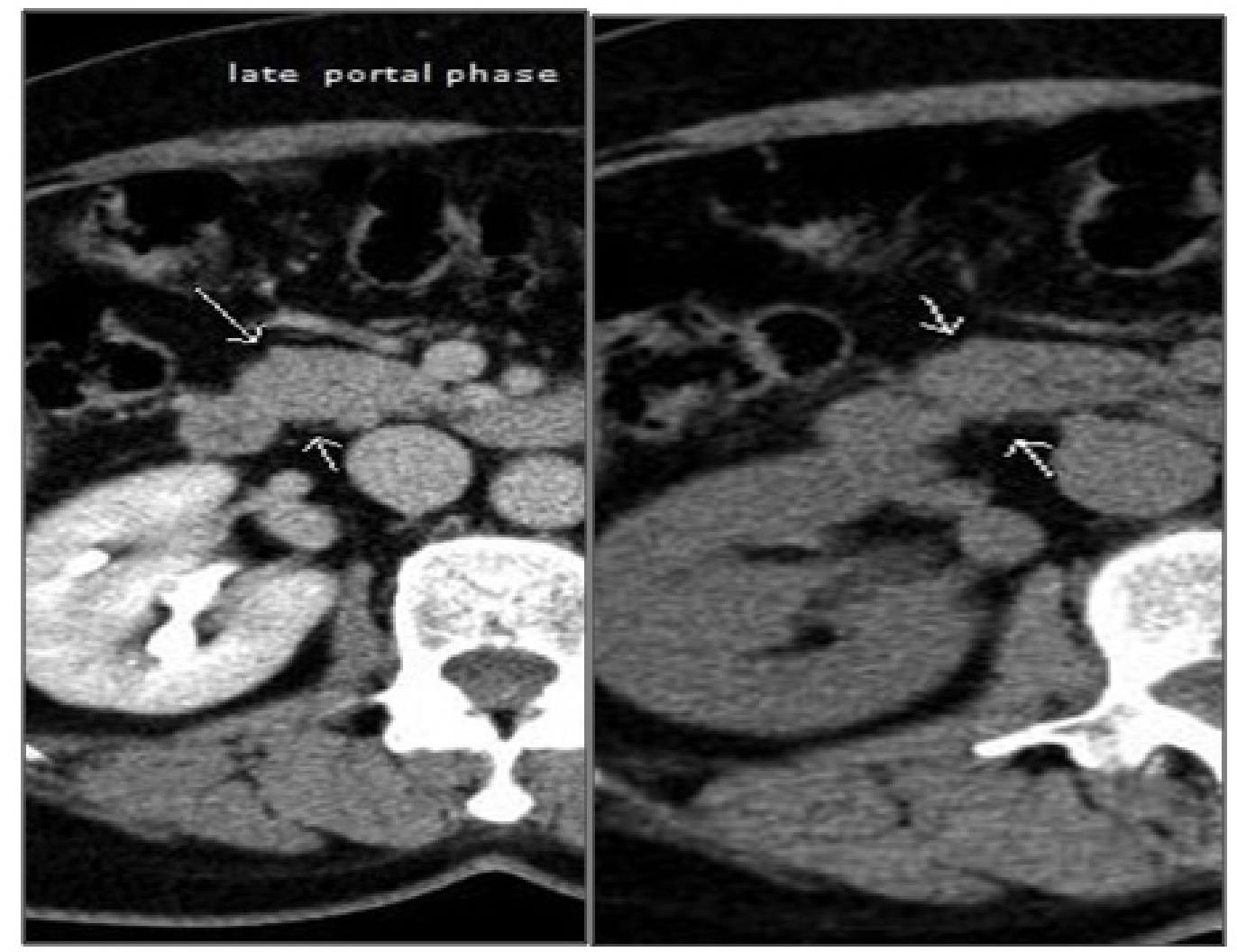

Figure 2 Computed tomography with contrast.

Citation: Gonçalves AP, Viegas C, Lourenço M, et al. Enucleation of pancreatic proinsulinoma: case report. Endocrinol Metab Int J. 2016;3(5):I I6-12I. DOI: $10.15406 / \mathrm{emij} .2016 .03 .00062$ 


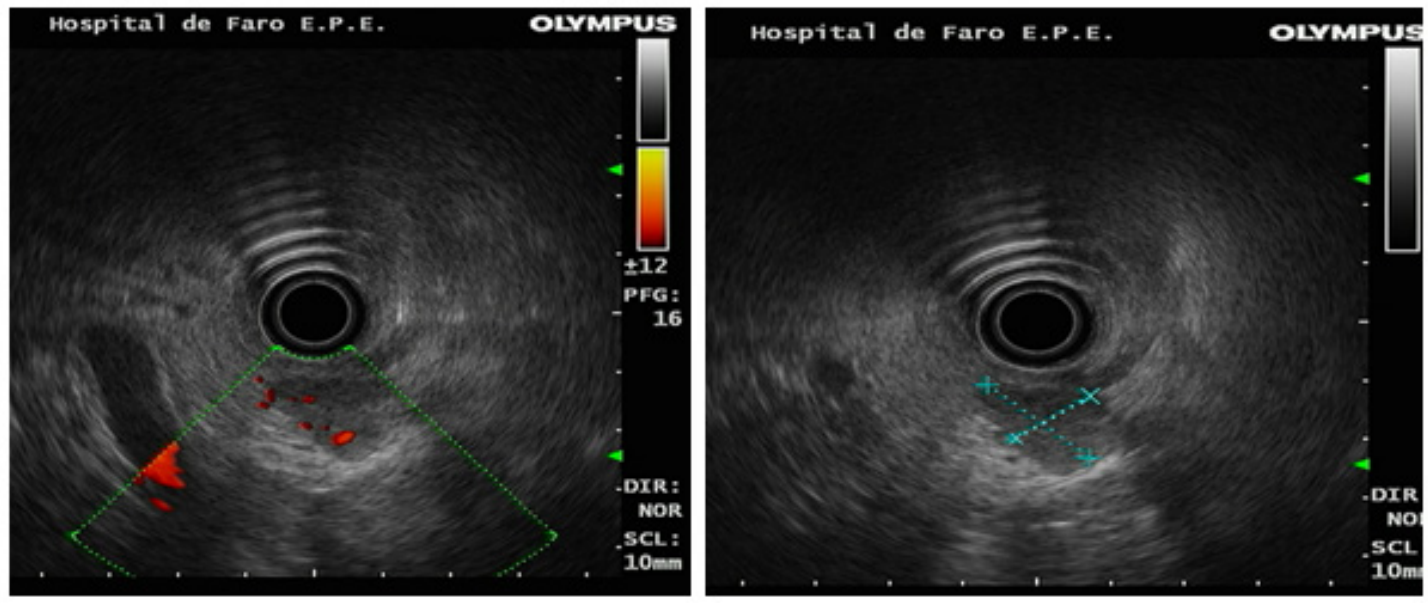

Figure 3 Eco-endoscopy with Doppler. Nodule hypoechoic, very vascularized and well-defined.
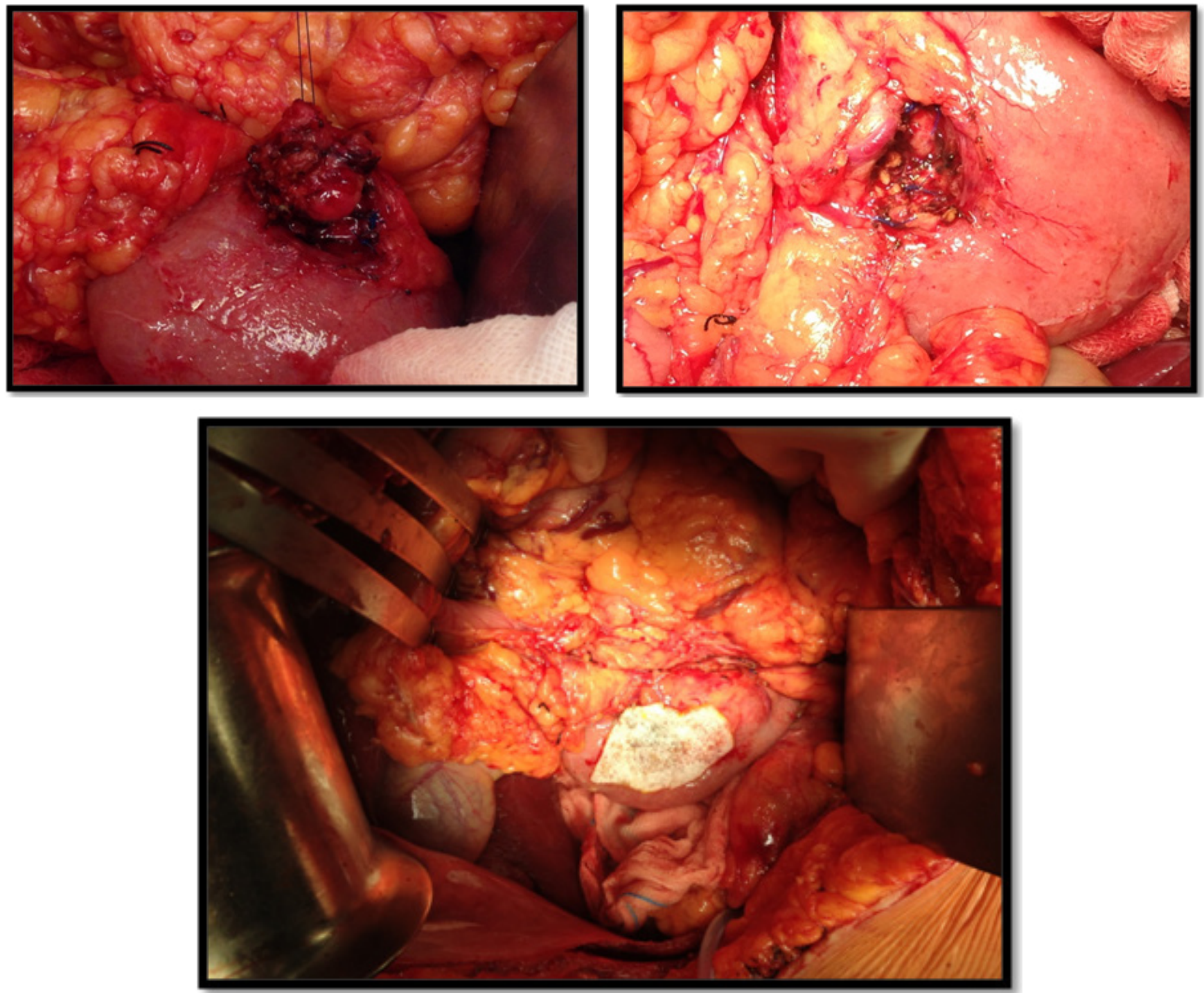

Figure 4 Surgery.Tumor enucleation.

Citation: Gonçalves AP, Viegas C, Lourenço M, et al. Enucleation of pancreatic proinsulinoma: case report. Endocrinol Metab Int J. 2016;3(5):I I6-121. DOI: $10.15406 / \mathrm{emij} .2016 .03 .00062$ 


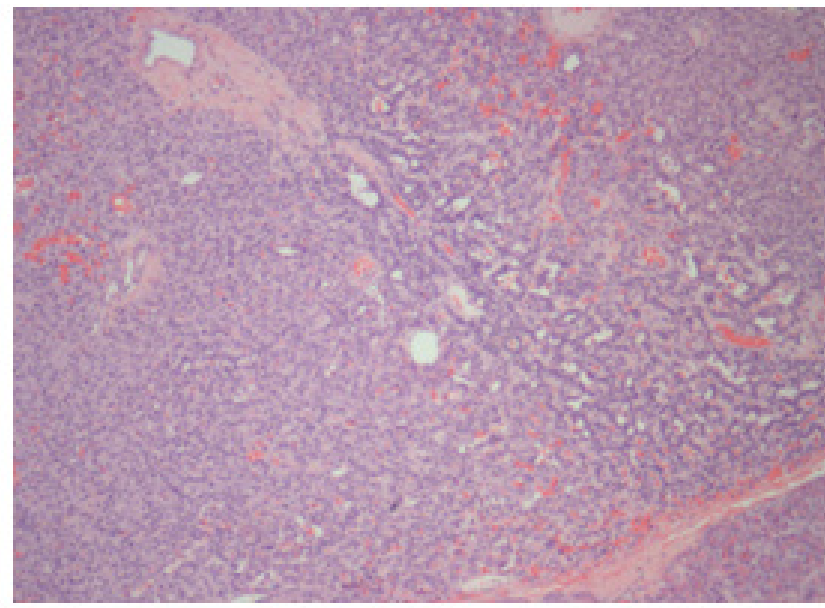

Figure 5A HE 10x: Low -power photomicrograph demostrating a neuroendocrine tumor. The tumor shows solid, ribbonlike, and acinar growth patterns.

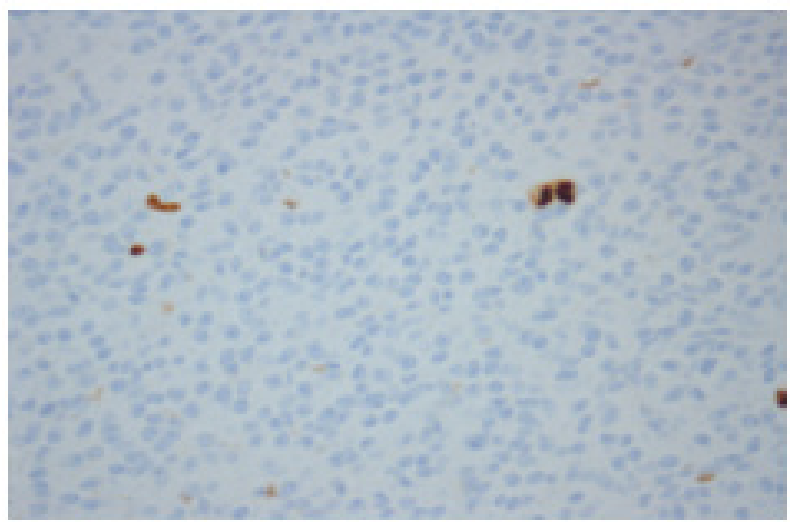

Figure 5C Low antibody staining against Ki-67 (nuclear protein present during all active phases of cell cycle and absent from resting cells).

\section{Discussion}

Functional islet beta-cell tumours are a common cause of endogenous hyperinsulinemia. It has an incidence of 2-4 individuals/million/ year and can occur sporadically or hereditarily in the context of endocrine neoplasia syndrome Multiple 1 (MEN 1) or von Hippel Lindau Disease. $^{2,3}$

Usually, functional islet beta-cells tumours produce simultaneously insulin and proinsulin. Functional islet beta-cells tumours producing only proinsulin, like the one described in this clinical case, are rare. ${ }^{4-6}$

Although the circulating proinsulin has only $20 \%$ of the bioactivity compared with insulin, during a fasting or period of high metabolic activity, the progressive decrease in blood glucose associated with failure in reducing proinsulin production results in hypoglycaemia. ${ }^{4}$ In our case, the patient reported symptoms suggestive of hypoglycaemia without a predictable pattern.

In the investigation of a suspected functional islet beta-cells tumour is important to note the type of test used to insulin dosage since,

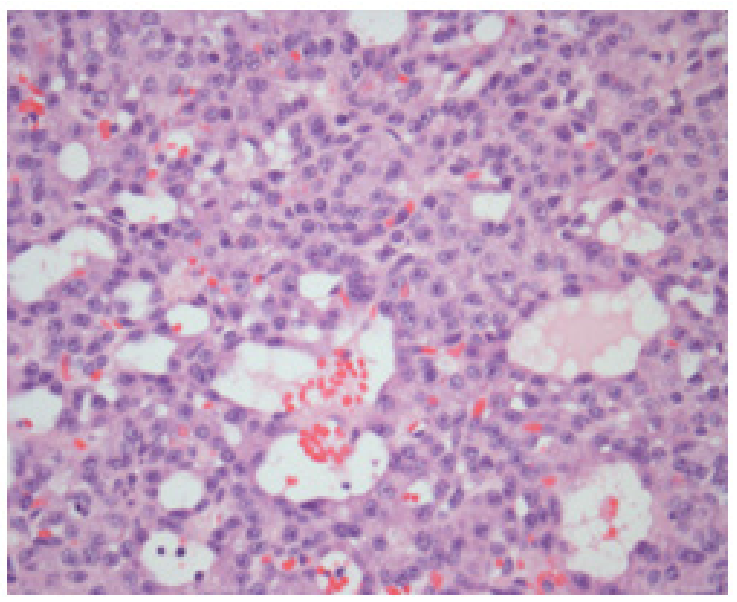

Figure 5B HE 40x: Higher magnification showing monomorphous cell, large nuclei and small nucleoli as well as inconspicuous cytoplasma and fine cromatina. Mitoses are rare.

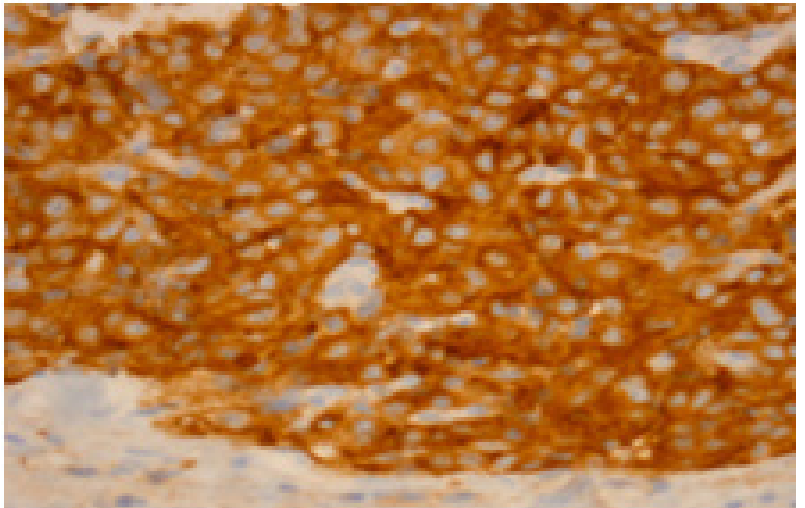

Figure 5D Intense staining against synaptophysin (citoplasmatic protein located in neurons and neuroendocrine tumors).

while some assays measure only the intact insulin molecule, other simultaneously measure proinsulin and C-peptide (40-80\% cross-reaction between proinsulin and insulin) ${ }^{4,6,7}$ Currently, most commonly used tests immunoradiometric (IRMA) or imunoquimioluminescentes (ICMA) which do not cross-react with proinsulin. Thus, in cases of suspected endogenous hyperinsulinemia it is critical specifically order proinsulin's dosage, as we did in the case described; otherwise there is the risk of delay or failure diagnosis. Tumour localization is also challenging. Imaging studies should only take place once the biochemical diagnosis has been established. Endoscopic ultrasound is the most sensitive and specific method.

In conclusion, endogenous hyperinsulinemia is a challenging diagnosis. The work-up of fasting hypoglycaemia is crucial because a wrong diagnosis can lead to unnecessary pancreatectomy or a missed pancreatic tumour. Highly specific serum insulin assay can difficult the diagnosis. As in this case, an enucleative approach minimizes the risk of developing post-operative diabetes, leading to a favourable prognosis.

\section{Acknowledgments}

None. 


\section{Conflicts of interest}

The author declares there are no conflicts of interest.

\section{References}

1. Cryer PE, Axelrod L, Grossman AB, et al. Evaluation and management of adult hypoglycemic disorders: an endocrine society clinical practice guideline. J Clin Endocrinol Metab. 2009;94(3):709-728.

2. Kronenberg H, Melmed S, Plonsky K. Williams Textbook of Endocrinology ( $11^{\text {th }}$ edn), USA, Saunders Elsevier, 2008.

3. Jameson J, De Groot L. Endocrinology-Adult and Pediatric $\left(6^{\text {th }}\right.$ edn $)$, USA, Saunders Elsevier, 2010.
4. Arioglu E, Gottlieb NA, Koch CA, et al. Natural history of a proinsuline-secreting insulinoma: from symptomatic hypoglycemia to clinical diabetes. J Clin Endocrinol Metab. 2000;85(10):3628-3630.

5. Coelho C, Druce M, Grossman AB. Diagnosis of insulinoma in a patient with hypoglycemia without obvious hyperinsulinemia. Nat Rev Endocrinol. 2009;5(11):628-631.

6. Fadini GP, Maran A, Valerio A, et al. Hypoglycemic syndrome in a patient with proinsulin-only secreting pancreatic adenoma (proinsulinoma). Case Rep Med. 2011(2011):1-5.

7. Vezzosi D, Bennet A, Fauvel J, et al. Insulin, peptide-C and proinsulin for the biochemical diagnosis of hypoglycemia related to endogenous hyperinsulinism. Eur J Endocrinol. 2007;157(1):75-83. 